\title{
Computed tomography in adults with atypical clinical presentation of acute appendicitis: comparison of findings with inflammatory serum markers
}

\author{
Murat Karul ${ }^{1 *}$, Maxim Avanesov ${ }^{1}$, Bjoern Philip Schoennagel ${ }^{1}$, Asmus Heumann ${ }^{2}$, Sarah Keller ${ }^{1}$, Simon Veldhoen ${ }^{1}$, Christian Hessler ${ }^{3}$, \\ Gerhard Adam' and Jin Yamamura' \\ *Correspondence: m.karul@uke.de \\ 'Department of Diagnostic and Interventional Radiology, University Medical Center Hamburg-Eppendorf, Hamburg, Germany. \\ 2Department of General, Visceral- and Thoracic Surgery, University Medical Center Hamburg-Eppendorf, Hamburg, Germany. \\ ${ }^{3}$ Department of Neurological Surgery, University Medical Center Hamburg-Eppendorf, Hamburg, Germany.
}

\begin{abstract}
Purpose: To evaluate both the potential usefulness of multidetector computed tomography (MDCT) in diagnosis of acute appendicitis (AA) in patients with atypical clinical presentation and to compare findings with C-reactive protein (CRP) and white cell count (WCC).

Materials and methods: MDCT images in 69 patients with atypical presentation of AA were retrospectively reviewed by two readers in consensus. Diagnostic accuracy, sensitivity, specificity, positive and negative predictive values (PPV/NPV) were assessed considering histopathological evaluation as reference. Patients with AA were grouped in nonperforated vs perforated and CRP/ WCC were correlated using both Chi-square-test $\left(\chi^{2}\right)$ and receiver operating characteristic (ROC) curve analysis.

Results: 39 patients underwent surgery and AA was confirmed histopathologically in 29/39 cases (74.4\%), showing nonperforated AA $(n=23,79.3 \%)$ and perforated AA $(n=6,20.7 \%)$. In the remaining $10 / 39$ patients $(25.6 \%)$ diverticulitis of sigmoid colon was diagnosed $(n=3)$; colitis $(n=4)$; cholecystitis $(n=3)$. Among the other 30/69 patients MDCT was either unremarkable $(n=18)$ or differentials were detected $(n=12)$. Diagnostic accuracy in patients with histopathologically confirmed AA was $95.7 \%$, sensitivity was $90.6 \%$, specificity was $93.6 \%$, PPV was $83.0 \%$, and NPV was $89.8 \%$. All MDCT findings but calcified appendicoliths and CRP/WCC correlated statistical significant when AA was confirmed histopathologically $\left(\chi^{2}=26.2 ; \mathrm{p}<0.001\right)$. In contrary to WCC $(\mathrm{p}=0.11)$, CRP was significantly higher in patients with perforated AA than nonperforated AA $(\mathrm{p}<0.01)$, demonstrating an optimal cut-off value $>121.5 \mathrm{mg} / \mathrm{L}$.

Conclusion: MDCT is required immediately to rule out perforation in patients with suspected AA despite atypical clinical presentation and a CRP level $>121.5 \mathrm{mg} / \mathrm{L}$.
\end{abstract}

Keywords: Appendicitis, multidetector computed tomography, c-reactive protein, white cell count

\section{Introduction}

Acute appendicitis (AA) is the most common cause of acute abdominal pain in adults $[\mathbf{1}, \mathbf{2}] .70 \%$ of patients have classical clinical features such as pain near the umbilicus that grows more intense over time and shifts to the right lower quadrant (RLQ), fever, and guarding at McBurney's point [3]. Those classical cases allow making a quick and safe diagnosis by patient's history, physical examination and elevated C-reactive protein (CRP) and white cell count (WCC) in serum analysis. In the remaining 30\% of the cases at least one of these classical findings is absent (the so-called atypical presentation of AA) [4]. These patients usually present with moderate abdominal pain that does not worsen or shift. Atypical clinical presentation of appendicitis is more frequent in certain patient groups (elderly, pregnant women, and particularly in patients with anatomical variations of the vermiform appendix relative to the cecum) and may result in diagnostic confusion, and risk of complication such as appendiceal perforation with abscess formation, peritonitis, and bowel obstruction [4-6]. A prompt diagnosis is rewarded by marked decrease in morbidity and mortality [7].

Multidetector computed tomography (MDCT) is well established for the diagnosis of AA in adults in several countries, e.g., the United States [8], showing a sensitivity of $90-100 \%$, a specificity of $90-99.1 \%$, a positive predictive value (PPV) of $90-95.7 \%$, and a negative predictive value (NPV) of $90-100 \%$, respectively $[1,9,10]$. MDCT is superior to transabdominal ultrasound in the diagnosis of appendicitis [11]. Signs of AA on MDCT are a thickened appendiceal wall above $2 \mathrm{~mm}$ with ringlike contrast enhancement, a cross-sectional diameter above 6 $\mathrm{mm}$, periappendiceal fat attenuation, a calcified appendicolith, and abscess formation in the RLQ [12-16].

In case of suspected AA taking of a blood sample is an important part of the clinical evaluation. But the diagnostic value of CRP and WCC remains a controversial issue as recent studies showed low diagnostic accuracy in AA for these inflammatory serum markers $[17,18]$. However, CRP and WCC cannot be relied 
Karul et al. Gastroenterological and Intestinal Systems 2013,

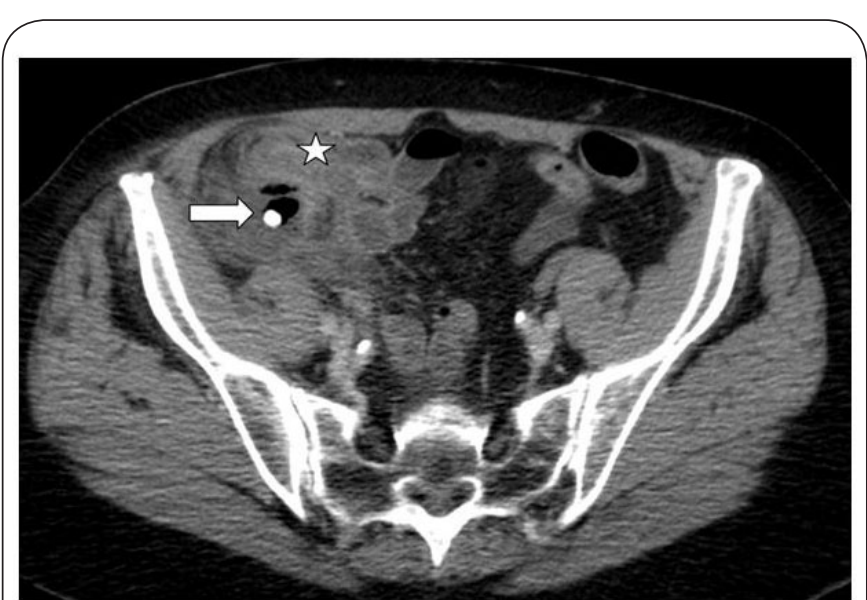

Figure 1. Axial MDCT image in a 75-year-old woman with perforated acute appendicitis demonstrates a calcified appendicolith (arrow) and a well-defined periappendiceal abscess (asterisk). Serum C-reactive protein level was 250 $\mathrm{mg} / \mathrm{L}$ and white cell count was $15.5 \times 10^{9} / \mathrm{L}$.

upon to make a specific diagnosis, but the inflammatory markers may be helpful in clinical decision making in those patients. None the less, a considerable amount of investigators constrain their diagnostic decisions based on whether the inflammatory serum markers are either elevated or not $[19,20]$.

A recent retrospective study evaluated the relationships between the severity of AA in patients with typical presentation as detected on MDCT and CRP/WCC [21]. CRP was found to correlate with MDCT determined stage of appendiceal inflammation and could be a predictor for perforation, where as WCC might be useful to detect early AA [21].

As far as we know, there have been no reports about the diagnostic accuracy of MDCT in the detection of AA in patients with atypical clinical presentation only, having regard to the comparison between MDCT findings and the inflammatory serum markers. Therefore, the aim of our study was both to assess the value of MDCT in the diagnosis of AA in patients with atypical clinical presentation and to determine the optimal cut-off value of CRP/WCC for histopathologically proven perforation.

\section{Materials and methods Patient population}

487 patients with typical clinical features of AA underwent emergency appendectomy without a preoperative MDCT scan in our university medical center between January 2009 and January 2012. The study group consisted of 69 consecutive patients (33 males; 36 females; age $54 \pm 17.4$ years; range 1890 years) with atypical clinical features of AA who had been referred for a MDCT scan during the same period of time. Subjects were selected according to the following inclusion and exclusion criteria:

\section{Inclusion criteria}

1. Criteria for atypical presentation of AA were: - mild to moderate abdominal pain that did not grow in intensity.

- absence of at least one of the classic findings of AA: pain near the navel that shifts in the RLQ $(n=45)$, fever $(n=5)$, and local tenderness and guarding at McBurney's point $(n=28)$.

- diffuse mild touch-sensitivity of the abdomen on the physical examination.

2. All women had normal findings in the gynecologic examination.

3. Histopathology results were available in patients who under went surgery immediately after the MDCT scan.

4. Image data was digitally available for retrospective analysis in our radiological information system (RIS).

\section{Exclusion criteria}

1. Pregnant women and children

- The study protocol has been approved by the local Clinical Institutional Review Board and complied with the Declaration of Helsinki. All subjects had given written informed consent for the retrospective evaluation of their data.

\section{MDCT acquisition and image reconstruction}

MDCT images were obtained using a 256-detector row CT scanner (Brilliance iCT; Philips Medical Systems, Best, the Netherlands). Patients were given $120 \mathrm{~mL}$ iomeprol (Imeron 300: Bracco, Konstanz, Germany) intravenously at a rate of $3 \mathrm{~mL} / \mathrm{sec}$ via the antecubital vein. All MDCT examinations were performed without enteric (oral or rectal) contrast agents. Imaging in inspiration started after 110 seconds from the diaphragm to the pubic symphysis $(120 \mathrm{kV}, 80 \mathrm{~mA}$, transaxial field of view $350 \mathrm{~mm}$, no gap, collimation $2 \mathrm{~mm} \mathrm{x}$ $128 \mathrm{~mm} \times 0.625 \mathrm{~mm}$, pitch 0.985 , gantry rotation time $0.33 \mathrm{~s}$ ). The radiation dose was adjusted according to the patients body size and body shape by automatic current selection (ACR; Dose-Right $\odot$; Philips Healthcare, Best, the Netherlands). Transaxial, sagittal, and coronal images were reconstructed from isotropic voxels with a slice thickness of $3 \mathrm{~mm}$ [22].

\section{Image analysis}

The transaxial and coronal MDCT images were evaluated independently by two readers ( 4 and 5 years of experience in abdominal imaging, respectively) blinded to all subjects' clinical information at a window range of 60-340 Hounsfield units (HU) on state-of-the-art GE Centricity RIS/PACS workstations. In case of disagreement between the two readers, who were aware that this was a study to diagnose AA, consensus was reached on a final reading for the statistical analyses [23].

MDCT images were visually evaluated for the presence of various appendicitis signs [12-16]: 


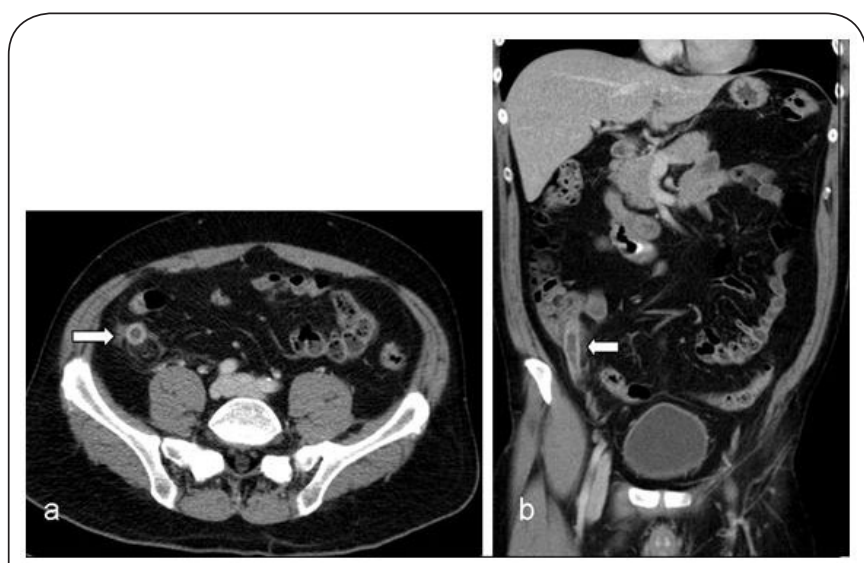

Figure 2. Axial (a) and coronal (b) MDCT images in a 45-year-old man show an appendiceal wall thickening (>2 $\mathrm{mm}$ ) with a cross-sectional diameter of $12 \mathrm{~mm}$ (arrows), and periappendiceal inflammatory changes. Serum C-reactive protein level was $140 \mathrm{mg} / \mathrm{L}$ and white cell count was $14.5 \times 10^{9} / \mathrm{L}$.

1. Periappendiceal abscess formation (Figure 1).

2. Wall thickness above $2 \mathrm{~mm}$ with ring-like contrast enhancement (Figure 2a).

3. Increased cross-sectional diameter above $6 \mathrm{~mm}$ (Figure 2b). 4. Periappendiceal fat attenuation (Figures $\mathbf{2 a}$ and $\mathbf{2 b}$ ).

5. Calcified appendicolith (Figure 1).

The first sign was used to detect appendiceal perforation. The combination of second, third, and fourth sign was used to diagnose nonperforated AA. The latter sign was considered as a secondary finding, and was not pathognomonic for the diagnosis of AA [24], especially when it was seen on MDCT images without appendiceal wall or adjacent fat abnormalities.

\section{Histopathological evaluation}

All surgical specimens were analyzed by pathologists with more than 5 years of experience. The histopathological diagnosis was based on changes and density of neutrophil, lymphocyte and eosinophil infiltration in the appendiceal wall. The severity of appendiceal inflammation was grouped in 4 histopathological conditions: phlegmonous, ulcero-phlegmonous, gangrenous, and perforation with abscess formation.

\section{Laboratory findings}

Blood samples were taken from the antecubital vein from all patients. Markers of inflammatory conditions were elevated WCC (normal range: $4.5-10 \times 10^{9} / \mathrm{L}$ ) and elevated CRP (normal range: $<5 \mathrm{mg} / \mathrm{L}$ ). Blood values were illustrated using box plot graphs.

\section{Statistical analysis}

The diagnostic accuracy, sensitivity, specificity, and positive and negative predictive value (PPV/NPV) of the MDCT findings were analysed using a contingency table. The Chi-square test $\left(x^{2}\right)$ was used to compare MDCT findings with mean inflammatory serum markers. Continuous variables were expressed as mean \pm SD. For between-group comparisons of continuous data, $\mathrm{p}$-values were calculated from Mann-Whitney's $U$ test for unpaired samples. Receiver operating characteristic (ROC) analysis was performed to define the optimal cut-off value for CRP. Statistical significance was established for 2-tailed p-values of less than 0.05 . Data collection and statistical calculations were performed using SPSS Statistics 21 (IBM Inc. SPSS Statistics) software.

\section{Results}

\section{MDCT findings and histopathological analysis in the} study group

Evaluation of MDCT scans was feasible in all 69 patients. AA was diagnosed in 32 patients (46.4\%) on MDCT using the defined signs of appendicitis. 39/69 patients (56.5\%) underwent emergency surgery (including all MDCT-positive patients) immediately after the diagnosis was made by MDCT examination. In these cases, histopathology confirmed the diagnosis of AA in $29 / 39$ patients (74.4\%). The three remaining MDCT-positive patients (4.3\%) were false-positive with a final diagnosis of perforated diverticulitis of the sigmoid colon. In those patients the appendix could not be identified retrospectively, because of abscess formation in the RLQ.

In the remaining $7 / 39$ patients (17.9\%) who underwent surgery, ischemic colitis was diagnosed on MDCT in 4 patients (10.2\%); and acute cholecystitis in 3 patients (7.7\%) with histopathologically confirmation, respectively. Among the remaining patients, who did not undergo surgery (30/69), colitis was diagnosed on MDCT $(n=5)$; urolithiasis $(n=3)$; pyelonephritis $(n=2)$, pancreatitis $(n=2)$, and MDCT was unremarkable $(n=18)$. None of these patients presented later with AA in our hospital.

\section{MDCT findings in patients with histopathologically} confirmed AA

In the 29 patients with histopathologically proven AA MDCT revealed nonperforated AA in 23 cases (79.3\%). All of them showed a thickened appendiceal wall above $2 \mathrm{~mm}$ with ring-like contrast material enhancement, a cross-sectional appendiceal diameter above $6 \mathrm{~mm}$, and periappendiceal fat attenuation. In the remaining 6 cases (20.7\%) appendiceal perforation with abscess formation in the RLQ was correctly identified with MDCT. A calcified appendicolith $(n=5)$ was found in patients with nonperforated AA as well as perforated AA.

Furthermore, the position of the inflammed appendix corresponded to the McBurney's point $(n=13)$, retrocecal $(n=9)$ (Figures 3a and 3b), periumbilical $(n=3)$ (Figures $4 a$ and $4 b$ ), retroileal $(n=2)$, pelvic $(n=1)$, and subcostal $(n=1)$.

\section{Laboratory findings}

In 23/29 patients (79.3\%) with nonperforated AA inflammatory 

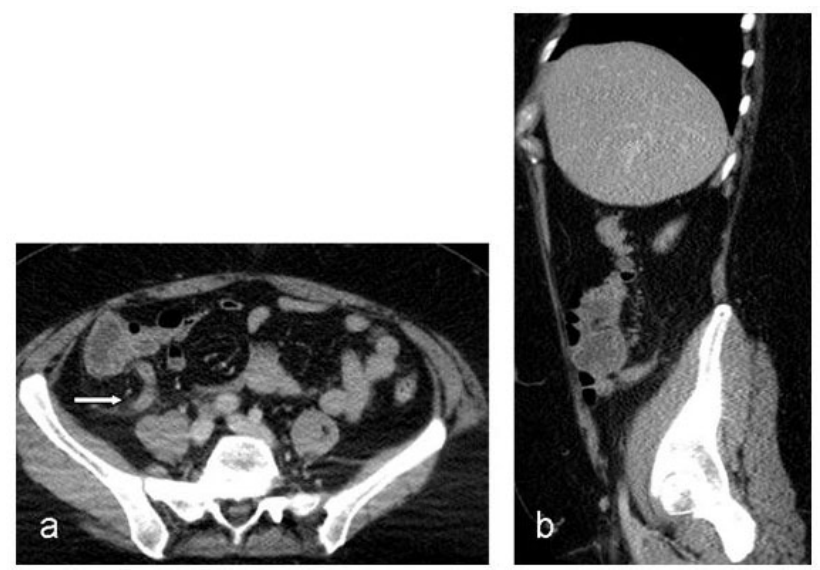

Figure 3. Retrocecal location of the inflamed appendix (arrow) in a 76-year-old man. Axial (a) and sagittal (b) MDCT images show a periappendiceal edema. Serum C-reactive protein level was $88 \mathrm{mg} / \mathrm{L}$ and white cell count was $11.5 \times 10^{9} / \mathrm{L}$.

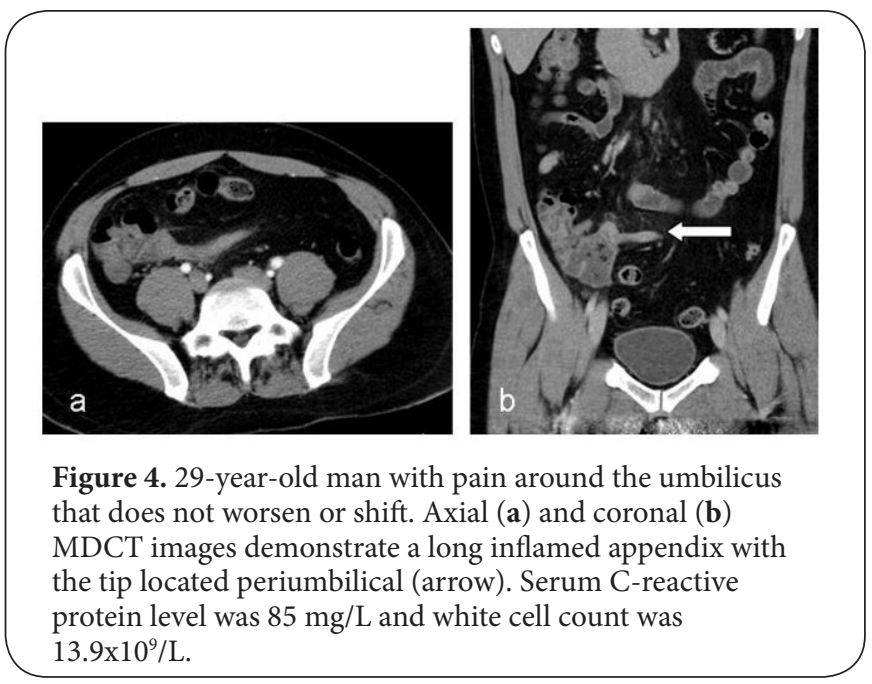

serum markers were slightly increased (mean CRP $58.7 \mathrm{mg} / \mathrm{L}$ \pm 53.3 ; range $0-162 /$ mean WCC $11.7 \times 10^{9} / \mathrm{L} \pm 2.1$; range $7.2-16.6$ ). Of them, 1 patient only had an elevated level of CRP, and 1 only leukocytosis. In all $6 / 29$ patients (20.7\%) with perforated AA CRP was highly elevated (mean CRP $237 \mathrm{mg} / \mathrm{L} \pm 92.3$; range 133-353), and mean WCC was moderately elevated (WCC 13.2×10\%/L \pm 1.4 ; range 11.5-14.7). In 3/32 MDCT-positive patients with a final diagnosis of perforated diverticulitis of the sigmoid colon CRP levels were highly elevated (mean CRP $177.3 \mathrm{mg} / \mathrm{L} \pm 24.0$; range 143-212).

Statistical analysis with histopathological correlation Statistical analysis revealed diagnostic accuracy of $95.7 \%$, sensitivity of $100 \%$, specificity of $93.6 \%$, PPV of $83.0 \%$, and NPV of $89.8 \%$ in the diagnosis of AA using MDCT. Inflammatory serum

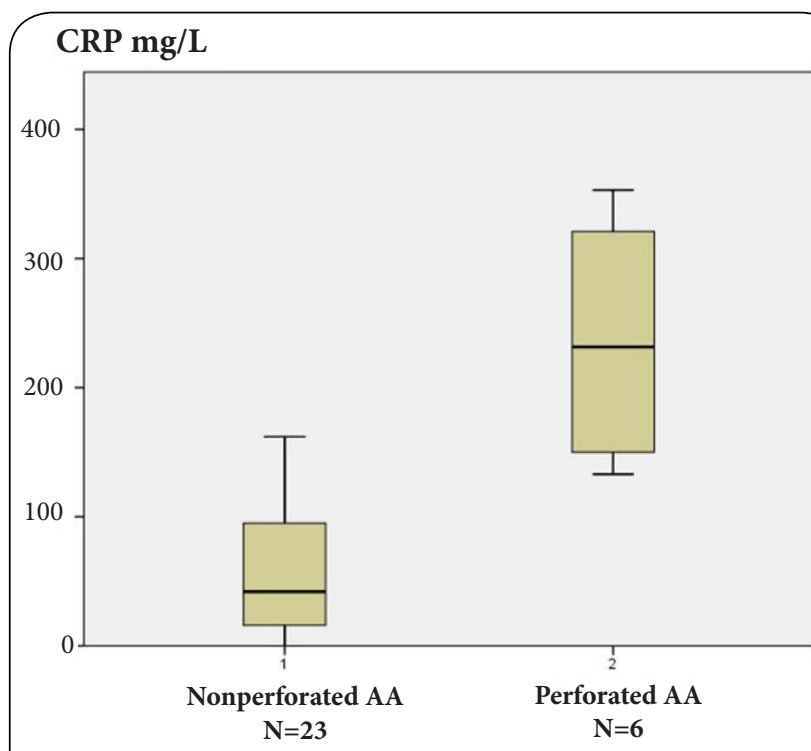

Figure 5. Comparison of C-reactive protein (CRP) between patients with nonperforated $(n=23)$ and perforated $(n=6)$ acute appendicitis. CRP was significantly higher in patients with perforation $(\mathrm{p}<0.01)$.

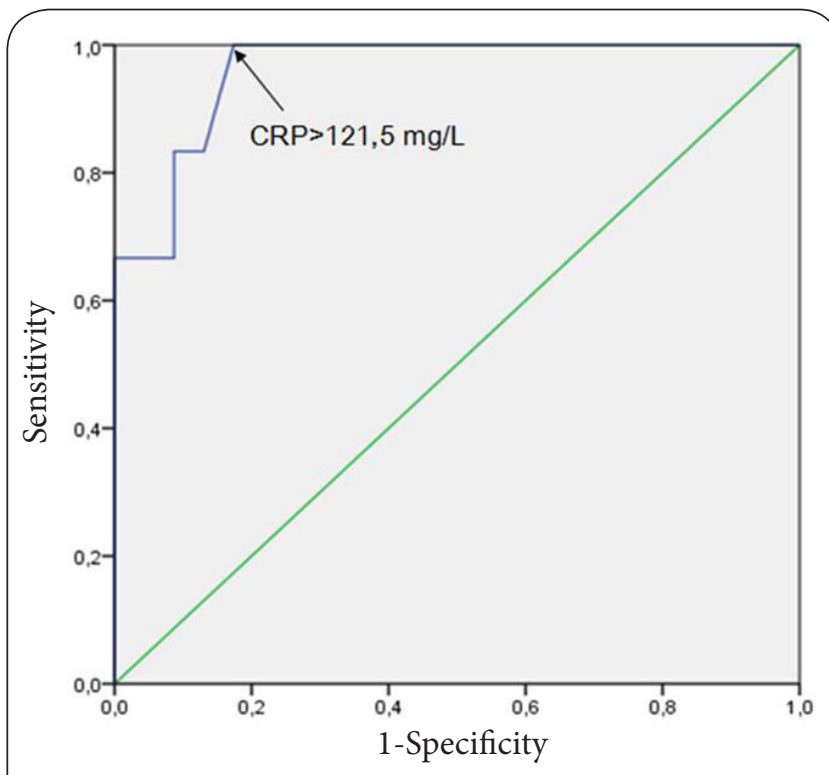

Figure 6. Receiver-operating characteristic curve for assessment of abscess due to appendiceal perforation as determined by serum C-reactive protein levels (AUC 0.96).

markers and all MDCT findings but calcified appendicoliths correlated statistical significant when AA was confirmed histopathologically $\left(x^{2}=26.2 ; p<0.001\right)$. CRP levels (Figure 5 ) were significantly higher for perforated $A A$ than for nonperforated AA ( $231.5 \pm 92.3$ vs $42 \pm 53.3, p<0.01)$. ROC analysis showed that the optimal threshold for differentiation of nonperforated and perforated AA was a CRP level $>121.5 \mathrm{mg} / \mathrm{L}$ 


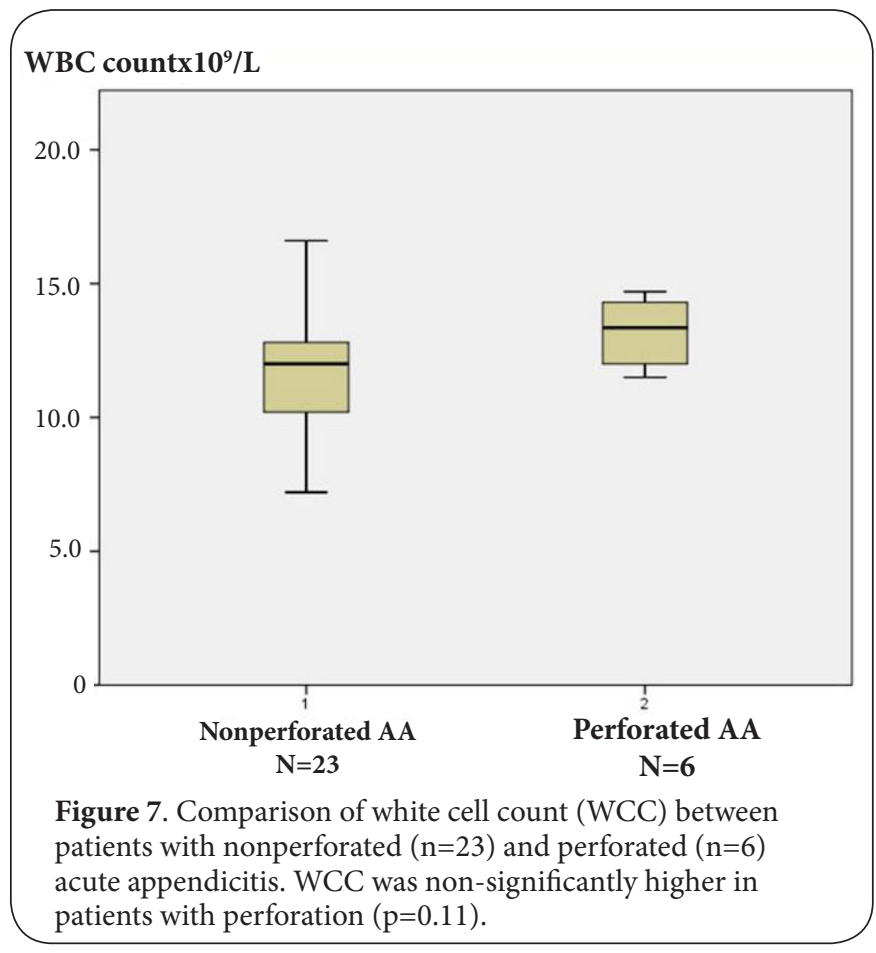

(AUC 0.96) (Figure 6), resulting in a sensitivity of $100 \%$ and a specificity of $82.6 \%$ for a $95 \%$ confidence interval: 0.892 to 1.000 with a standard error of 0.35. WCC (Figure 7) was nonsignificantly higher for perforated $A A$ than for nonperforated AA $(13.4 \pm 1.4$ vs $12 \pm 2.1, p=0.11)$.

\section{Discussion}

Our results demonstrate high diagnostic accuracy of MDCT in the diagnosis of AA in patients with atypical clinical presentation, particularly in the detection of abscess formation in the RLQ. In patients with nonperforated AA $(n=23) C R P$ and WCC were slightly elevated (except of 2 cases with normal levels of CRP or WCC, respectively). When appendiceal perforation was histopathologically confirmed $(n=6), C R P$ was highly elevated showing an optimal cut-off point more than $121.5 \mathrm{mg} / \mathrm{L}(\mathrm{p}<0.01)$. In contrast, WCC was moderately raised and the cut-off point was non-significantly $(p=0.11)$.

These findings suggest that further diagnostic workup is immediately required in those patients to reduce both complication and negative appendectomy rate. But not all patients should undergo MDCT regarding the radiation dose and the costs. We recommend the following diagnostic algorithm to confirm or r/o AA: When AA is diagnosed on transabdominal ultrasound and moreover, CRP levels are higher than 121.5 $\mathrm{mg} / \mathrm{L}$ patients should undergo urgent appendectomy. When transabdominal ultrasound was not groundbreaking, gynecologic examination should be performed principally in women to exclude differential diagnosis such as adnexitis or tubo-ovarian abscess.
Furthermore, abdominal magnetic resonance imaging (MRI) without contrast administration is the method of first choice in women in childbearing age and pregnant women (hence, we excluded pregnant women from our study) with persistent suspicion of AA [25]. Additionally, MRI should be performed in young men with suspected AA. In postmenopausal women and older men MDCT (with or without contrast administration) is recommendable. However, in case of suspected perforation considering CRP levels more than $121.5 \mathrm{mg} / \mathrm{L}$ MDCT with administration of intravenous contrast material is essential to detect signs of AA e.g., ring-like contrast-enhancement of the thickened appendiceal wall and abscess formation in the RLQ [12,13].

On the contrary, a recent study assessed the levels of CRP/ WCC in the diagnosis of AA without preoperative MDCT scan [26]. No patients with WCC/CRP both in the normal range had AA. The authors conclude that WCC and CRP were poor positive predictors of $A A$, both alone and in combination, and correlated poorly with the development of complications. There are several reasons for atypical clinical presentation of AA: First, the abnormal location of the appendix relative to the cecum [27]. When the inflamed appendix is located retrocecal or retroileal ( $11 / 29$ cases in our study) it is shielded from the anterior peritoneal wall by the overlying cecum and ileum. Therefore, the abdominal pain seems mild to moderate and the classic shift of pain from around the navel to the RLQ may be absent. With AA in pelvic position ( $1 / 29$ cases in our study), pain is often localized to the lower abdomen. Second, abdominal pain in elderly patients may be minimal and fever may not occur (5/29 cases in our study) [28]. Finally, the diagnosis of AA in pregnant women is difficult because of upward displacement of the cecum and a position of the appendix in the right subcostal area [29].

A limitation of this study is the retrospective design and the limited numbers of patients. Besides, we disregarded the clinical experience of the referring abdominal surgeon and we did not use a clinical appendicitis scoring system [30]. At same time, we did not apply enteric contrast material, because some investigators state that these did not contribute to a better diagnostic accuracy [31]. Furthermore, the patients have a longer stay in the emergency room resulting in a delay in surgical treatment. In controversy, other studies claim that enteric contrast agents reduce the number of false-negative cases, showing further findings of AA such as the arrowhead sign, the "cecal bar" sign, and focal cecal apical thickening [32].

\section{Conclusion}

MDCT and a markedly elevated CRP level (optimal cut-off point more than $121.5 \mathrm{mg} / \mathrm{L}$ ) taken together are highly accurate in the diagnosis of perforation in patients with atypical clinical presentation of AA.

\section{Competing interests}

The authors declare that they have no competing interests. 
Karul et al. Gastroenterological and Intestinal Systems 2013,

\section{Authors' contributions}

\begin{tabular}{|l|c|c|c|c|c|c|c|c|c|}
\hline Authors' contributions & MK & MA & BS & AH & SK & SV & CH & GA & JY \\
\hline $\begin{array}{l}\text { Research concept and } \\
\text { design }\end{array}$ & $\checkmark$ & -- & -- & -- & -- & -- & -- & -- & $\checkmark$ \\
\hline $\begin{array}{l}\text { Collection and/or } \\
\text { assembly of data }\end{array}$ & -- & -- & -- & $\checkmark$ & -- & $\checkmark$ & -- & -- & -- \\
\hline $\begin{array}{l}\text { Data analysis and } \\
\text { interpretation }\end{array}$ & $\checkmark$ & -- & -- & -- & $\checkmark$ & -- & -- & -- & $\checkmark$ \\
\hline Writing the article & $\checkmark$ & $\checkmark$ & -- & -- & -- & -- & -- & -- & -- \\
\hline $\begin{array}{l}\text { Critical revision of the } \\
\text { article }\end{array}$ & -- & -- & $\checkmark$ & -- & -- & -- & -- & $\checkmark$ & $\checkmark$ \\
\hline Final approval of article & $\checkmark$ & -- & -- & -- & -- & -- & -- & -- & -- \\
\hline Statistical analysis & -- & $\checkmark$ & -- & -- & -- & -- & $\checkmark$ & -- & -- \\
\hline
\end{tabular}

Acknowledgement

We would like to thank the reviewers and the editor for

helpful comments on earlier versions of this manuscript.

Publication history

Editor: Stelios F. Assimakopoulos, University Hospital of Patras,

Greece.

Received: 06-Oct-2013 Revised: 25-Oct-2013

Accepted: 29-Oct-2013 Published: 16-Nov-2013

\section{References}

1. Petroianu A. Diagnosis of acute appendicitis. Int J Surg. 2012; 10:115-9. | Article | PubMed

2. Chalazonitis AN, Tzovara I, Sammouti E, Ptohis N, Sotiropoulou E, Protoppapa E, Nikolaou V and Ghiatas AA. CT in appendicitis. Diagn Interv Radiol. 2008; 14:19-25. | Pdf | PubMed

3. Ebell MH. Diagnosis of appendicitis: part II. Laboratory and imaging tests. Am Fam Physician. 2008; 77:1153-5. | Article | PubMed

4. See TC, Ng CS, Watson CJ and Dixon AK. Appendicitis: spectrum of appearances on helical CT. Br J Radiol. 2002; 75:775-81. | Article | PubMed

5. Stabile lanora AA, Moschetta M, Lorusso V and Scardapane A. Atypical appendicitis: diagnostic value of volume-rendered reconstructions obtained with 16-slice multidetector-row CT. Radiol Med. 2010; 115:93104. | Article | PubMed

6. Pinto Leite N, Pereira JM, Cunha R, Pinto P and Sirlin C. CT evaluation of appendicitis and its complications: imaging techniques and key diagnostic findings. AJR Am J Roentgenol. 2005; 185:406-17. | Article | PubMed

7. Wagner JM, McKinney WP and Carpenter JL. Does this patient have appendicitis? JAMA. 1996; 276:1589-94. | Article | PubMed

8. Reich B, Zalut T and Weiner SG. An international evaluation of ultrasound vs. computed tomography in the diagnosis of appendicitis. Int J Emerg Med. 2011; 4:68. | Article | PubMed Abstract | PubMed Full Text

9. Pooler BD, Lawrence EM and Pickhardt PJ. MDCT for suspected appendicitis in the elderly: diagnostic performance and patient outcome. Emerg Radiol. 2012; 19:27-33. | Article | PubMed

10. Tamburrini S, Brunetti A, Brown M, Sirlin C and Casola G. Acute appendicitis: diagnostic value of nonenhanced $C T$ with selective use of contrast in routine clinical settings. Eur Radiol. 2007; 17:2055-61. | Article | PubMed

11. van Randen $A$, Lameris W, van Es HW, van Heesewijk HP, van Ramshorst B, Ten Hove W, Bouma WH, van Leeuwen MS, van Keulen EM, Bossuyt PM, Stoker J and Boermeester MA. A comparison of the accuracy of ultrasound and computed tomography in common diagnoses causing acute abdominal pain. Eur Radiol. 2011; 21:1535-45. | Article | PubMed Abstract | PubMed Full Text
12. Kim HC, Yang DM, Kim SW and Park SJ. Reassessment of CT images to improve diagnostic accuracy in patients with suspected acute appendicitis and an equivocal preoperative CT interpretation. Eur Radiol. 2012; 22:1178-85. | Article | PubMed

13. Lai V, Chan WC, Lau HY, Yeung TW, Wong YC and Yuen MK. Diagnostic power of various computed tomography signs in diagnosing acute appendicitis. Clin Imaging. 2012; 36:29-34. | Article | PubMed

14. Karabulut N, Boyaci N, Yagci B, Herek D and Kiroglu Y. Computed tomography evaluation of the normal appendix: comparison of lowdose and standard-dose unenhanced helical computed tomography. J Comput Assist Tomogr. 2007; 31:732-40. | Article | PubMed

15. Moteki T, Ohya $\mathrm{N}$ and Horikoshi $\mathrm{H}$. Evaluation of the maximum depth of intraluminal appendiceal fluid to diagnose appendicitis with a 64-detector row CT scanner. J Comput Assist Tomogr. 2011; 35:703-10. | Article | PubMed

16. Raman SS, Kadell BM, Vodopich DJ, Sayer J, Cryer H and Lu DS. Patient gender-related performance of nonfocused helical computed tomography in the diagnosis of acute appendicitis. J Comput Assist Tomogr. 2003; 27:583-9. | Article | PubMed

17. Kessler N, Cyteval C, Gallix B, Lesnik A, Blayac PM, Pujol J, Bruel JM and Taourel P. Appendicitis: evaluation of sensitivity, specificity, and predictive values of US, Doppler US, and laboratory findings. Radiology. 2004; 230:472-8. | Article | PubMed

18. Johansson EP, Rydh A and Riklund KA. Ultrasound, computed tomography, and laboratory findings in the diagnosis of appendicitis. Acta Radiol. 2007; 48:267-73. | Article | PubMed

19. Ortega-Deballon P, Ruiz de Adana-Belbel JC, Hernandez-Matias A, GarciaSeptiem $J$ and Moreno-Azcoita M. Usefulness of laboratory data in the management of right iliac fossa pain in adults. Dis Colon Rectum. 2008; 51:1093-9. | Article | PubMed Abstract | PubMed Full Text

20. Khan MN, Davie E and Irshad K. The role of white cell count and C-reactive protein in the diagnosis of acute appendicitis. J Ayub Med Coll Abbottabad. 2004; 16:17-9. | Article | PubMed

21. Kim HC, Yang DM, Lee CM, Jin W, Nam DH, Song JY and Kim JY. Acute appendicitis: relationships between CT-determined severities and serum white blood cell counts and C-reactive protein levels. BrJ Radiol. 2011; 84:1115-20. | Article | PubMed Abstract | PubMed Full Text

22. Johnson PT, Horton KM, Mahesh M and Fishman EK. Multidetector computed tomography for suspected appendicitis: multi-institutional survey of 16-MDCT data acquisition protocols and review of pertinent literature. J Comput Assist Tomogr. 2006; 30:758-64. | Article | PubMed

23. Jan YT, Yang FS and Huang JK. Visualization rate and pattern of normal appendix on multidetector computed tomography by using multiplanar reformation display. J Comput Assist Tomogr. 2005; 29:446-51. | Article I PubMed

24. Lane MJ, Katz DS, Ross BA, Clautice-Engle TL, Mindelzun RE and Jeffrey $\mathrm{RB}$, Jr. Unenhanced helical CT for suspected acute appendicitis. AJR Am J Roentgenol. 1997; 168:405-9. | Article | PubMed

25. Avcu S, Cetin FA, Arslan H, Kemik O and Dulger AC. The value of diffusion-weighted imaging and apparent diffusion coefficient quantification in the diagnosis of perforated and nonperforated appendicitis. Diagn Interv Radiol. 2013; 19:106-10. | Article | PubMed

26. Sengupta $A, B a x G$ and Paterson-Brown S. White cell count and C-reactive protein measurement in patients with possible appendicitis. Ann R Coll Surg Engl. 2009; 91:113-5. | Article | PubMed Abstract | PubMed Full Text

27. Kim S, Lim HK, Lee JY, Lee J, Kim MJ and Lee AS. Ascending retrocecal appendicitis: clinical and computed tomographic findings. J Comput Assist Tomogr. 2006; 30:772-6. | Article | PubMed

28. Saddique M, Iqbal P, Rajput A and Kumar R. Atypical presentation of appendicitis: Diagnosis and management. J Surg Pak. 2009; 14:157-60. I Pdf

29. Oto A, Srinivasan PN, Ernst RD, Koroglu M, Cesani F, Nishino T and Chaljub G. Revisiting MRI for appendix location during pregnancy. AJR Am J Roentgenol. 2006; 186:883-7. | Article | PubMed

30. Yildirim E, Karagulle E, Kirbas I, Turk E, Hasdogan B, Teksam M and 
Karul et al. Gastroenterological and Intestinal Systems 2013,

Coskun M. Alvarado scores and pain onset in relation to multislice CT findings in acute appendicitis. Diagn Interv Radiol. 2008; 14:14-8. | Pdf | PubMed

31. Keyzer C, Cullus P, Tack D, De Maertelaer V, Bohy P and Gevenois PA. MDCT for suspected acute appendicitis in adults: impact of oral and IV contrast media at standard-dose and simulated low-dose techniques. AJR Am J Roentgenol. 2009; 193:1272-81. | Article | PubMed

32. Rao PM. Cecal apical changes with appendicitis: diagnosing appendicitis when the appendix is borderline abnormal or not seen. J Comput Assist Tomogr. 1999; 23:55-9. | Article | PubMed

\section{Citation:}

Karul M, Avanesov M, Schoennagel BP, Heumann A, Keller S, Veldhoen S, Hessler C, Adam G and Yamamura J. Computed tomography in adults with atypical clinical presentation of acute appendicitis: comparison of findings with inflammatory serum markers. Gasteroentrol Intest Syst. 2013; 1:1.

http://dx.doi.org/10.7243/2054-4154-1-1 